\title{
¡Hoy no hay fútbol! La huelga de futbolistas de 1948 vista desde la prensa peronista
}

Today there's no football! The 1948 strike of footballers seen by the Peronist press

\author{
ENRICO MONTANARI \\ Universidad Autónoma de Madrid \\ e.horus89@gmail.com
}

Resumen: En 1948 la mayoría de los futbolistas argentinos entraron en huelga contra los clubes y la federación argentina. Las peticiones de los jugadores comprendían una mejora salarial, una mayor flexibilidad contractual y, en general, poder acceder a las conquistas sociales que consiguieron los trabajadores en esos años. La huelga es un momento clave para el deporte argentino, que marca un punto de cambio para los años futuros. Este trabajo intenta mostrar la relación entre trabajo y deporte profesional a través del análisis de la prensa peronista de la época.

Palabras clave: Huelga, Fútbol, Peronismo, Prensa, Deporte.

Abstract: In 1948 the majority of professional footballers of the Argentinian First Division went to a strike against their respective teams and against the federation. Their goal was to get new salary conditions, a major contractual flexibility and, in general, to reach the same social conquests that the Argentinian workers got during those years. This work tries to analyse the relationship between professional sport and work through the Peronist press.

Keywords: Strike, football, Peronism, press, sport.

Recibido: 15 de mayo de 2017; aceptado: 4 de noviembre de 2017; publicado: 27 de marzo de 2018. Revista Historia Autónoma, 12 (2018), pp. 191-204.

e-ISSN: 2254-8726; DOI: https://doi.org/10.15366/rha2018.12.010. 
Este trabajo quiere aclarar un aspecto del mundo del deporte muchas veces poco considerado por los expertos del tema: la relación entre deporte y trabajo. En particular, quiero analizar cómo la huelga de jugadores de 1948 fue recibida y tratada por la prensa de la época y, para ello, utilizaré como fuente primaria los diarios peronistas El Laborista, Democracia y La Época. La pregunta que se quiere responder es la siguiente: ¿cómo la prensa peronista se posicionó en la pelea entre jugadores y clubes?

Este tema todavía no ha sido suficientemente estudiado. En un ensayo titulado La Huelga de Jugadores de $1948^{1}$ los historiadores Julio Frydemberg y Daniel Sazbon hacen un resumen de los hechos de la huelga, indicando también los factores de contestación y los actores que participan en el conflicto (jugadores, dirigentes deportivos y estatales) y llegan a la conclusión de que

\begin{abstract}
"el poder de intervención del gobierno peronista en ciertas áreas de la sociedad civil tuvo límites más marcados de lo que se suele reconocer. La capacidad que demostraron los clubes para defender su autonomía frente a la acción estatal para disciplinarlos resulta reveladora acerca de los límites del paradigma interpretativo que tradicionalmente se tiende a pensar la naturaleza de las relaciones entre peronismo y deporte"2.
\end{abstract}

El ensayo de Frydemberg y Sazbon no se centra mucho en la prensa ya que solo se cuenta con unas pocas páginas donde se resume la posición de algunos diarios y de algunas revistas locales acerca de la cuestión (cuanto más favorable al gobierno era el medio mayor fue el apoyo a las demandas de los futbolistas) pero no se adentra mucho en el análisis en profundidad de la prensa. Este trabajo no quiere cuestionar el análisis de Frydemberg y Sazbon, sino analizar cómo la prensa cercana al peronismo se relacionó con la huelga de los futbolistas, cuáles fueron las posiciones iniciales y cómo se modificaron a medida que se desarrolló la huelga.

Tres han sido los diarios de Buenos Aires elegidos para este trabajo: El Laborista, Democracia y La Época. Los tres fueron diarios muy cercanos al gobierno peronista y formaban parte de la misma empresa editora (el grupo ALEA, aunque La Época fue adquirida en 1951) que publicaba también La Razón, Noticias Gráficas y otros diarios menores del interior. Los tres diarios fueron sostenedores del peronismo desde el comienzo, tanto que en 1977 José Gobello, escritor, poeta y ensayista comentó así: "En 1946 toda la prensa de Buenos Aires, porque entonces sumaba millones de ejemplares, empuntó sus cañones contra la candidatura del coronel Perón. El coronel solamente tenía dos pequeños diarios; uno de 7000 ejemplares llamado Democracia, y El Laborista" . Otro factor importante que caracteriza estos diarios como peronistas fue sus intervenciones y, en el caso de Democracia, su cierre después de la Revolución Libertadora

\footnotetext{
${ }^{1}$ Frydembreg Julio y Daniel Sazbon, "La huelga de jugadores de 1948", en Rein, Raanan (comp.), La cancha Peronista. Fútbol y política (1946-1955), Buenos Aires, Universidad Nacional de San Martín, 2015, pp. 65-80.

${ }^{2}$ Ibídem, p. 80.

${ }^{3}$ Ulanovsky Carlos, Paren las Rotativas. Diarios, revistas y periodistas (1920-1969), Buenos Aires, Emecé, 2015, p. 120.
} 
(el golpe de Estado que en 1955 puso término al gobierno de Perón). La visión de estos tres diarios, muy cercanos al oficialismo pero que no formaban parte directamente, por lo menos no en 1948, del conjunto mediático oficialista puede darnos una buena mirada de esa específica área de la Argentina de la época ${ }^{4}$.

Los años cuarenta fueron muy complejos para Argentina. En junio de 1943 el gobierno de Ramón Castillo fue derrocado por un golpe militar organizado por un grupo de oficiales del ejército guiados primero por el general Arturo Rawson y después por el general Pablo Pedro Ramírez. La acción del grupo de militares, denominado $G O U$, se puede considerar inspirada por ideales nacionalistas, en particular en cuanto a la industria, anticomunistas y ser contrarias a las fuerzas aliadas que en este periodo estaban luchando en la Segunda Guerra Mundial (Argentina entró en guerra solo en 1945 cuando los aliados ya habían ganado el conflicto). La Confederación General del Trabajo, fundada en 1930, encontró mucha represión en un primer momento pero también vivió un periodo de crecimiento importante bajo la presidencia del general Juan Domingo Perón en la Dirección Nacional del Trabajo y en el Ministerio del Trabajo $^{5}$. Dicho crecimiento se consolidó el 17 de octubre 1945 con la liberación de Perón de la cárcel y después permitiendo al General de ganar las elecciones presidenciales el año sucesivo y de mantener el poder hasta el 1955.

El fútbol en Argentina fue importado por los ingleses en los años sesenta del siglo XIX y al comienzo este deporte se estableció como el signo distintivo de la comunidad inglesa de Buenos Aires. A principios del siglo xx el fútbol empezó a difundirse de manera masiva en varios estratos de la población. En 1891 se creó la primera liga oficial, la Argentine Association Football League (no hay que confundir esta liga con la Asociación de Fútbol Argentino, que se formó en los años treinta), entre equipos ingleses como el Alumni Athletic Club. Entre 1901 y 1910 se fundaron muchos clubes (entre los cuales los cinco grandes clubes porteños River Plate, Boca Juniors, San Lorenzo, Racing Avellaneda e Independiente). El fútbol se volvió rápidamente el deporte más popular junto con el boxeo y el automovilismo y los clubes, que empezaron siendo clubes barriales, vieron un crecimiento masivo en los primeros treinta años del siglo xx, cuando se creó la primera liga profesional en 1931 y la Asociación de Fútbol Argentino (AFA) en 1934․ Durante los años peronistas, el fútbol era seguramente el deporte más difundido del país con un promedio de más de 12000 entradas por partido en 1946, las que subieron a 15000 hacia finales de 19557. Cuando en 1948 sucedieron los hechos que llevaron a la huelga, el deporte argentino estaba todavía en una situación de transición entre amateurismo

\footnotetext{
${ }^{4}$ La historia de La Época es complicada siendo un diario peronista pero que tuvo una relación particular con el gobierno de Perón. Gambini, Hugo, Historia del Peronismo. Vol. 3: La violencia, Buenos Aires, DeBolsillo, 2016, capítulo 16.

${ }^{5}$ Schiavi, Marcos, El poder sindical en la Argentina Peronista (1926-1955), Buenos Aires, Immago Mundi, 2013.

${ }^{6}$ Sobre el periodo que va desde la primera liga hasta la llegada del profesionalismo, Frydemberg, Julio, Historia Social del Fútbol, del amateurismo a la profesionalización, Buenos Aires, Siglo XXI, 2013.

${ }^{7}$ Molinari Alejandro, y Roberto Martínez, El Fútbol. La conquista popular de una pasión argentina, Buenos Aires, Editorial de la Cultura Urbana, 2013, p. 185.
} 
y profesionalismo. El debate estaba muy sentido no solo en el país, sino en todo el ambiente deportivo mundial; el Comité Olímpico Internacional anuló la regla que impedía a los deportistas profesionales participar en los Juegos Olímpicos en los años sesenta porque estaba anclado a una concepción clásica del deporte que indica que este no debe tener afán de lucro ${ }^{8}$. Hay que tener en consideración esta situación al analizar el comportamiento de los sujetos en la gestión de la huelga y los resultados que los futbolistas consiguieron.

\section{El comienzo del conflicto}

A inicios de abril de 1948, más de ciento treinta jugadores profesionales se juntaron en el estadio de la Federación Argentina de Box, en la calle Castro Barros, para la reunión de los miembros de Futbolistas Argentinos Agremiados (FAA) ${ }^{9}$ y decidieron rechazar completamente la nueva reglamentación de la AFA. Con este acto, empezó la gran huelga de futbolistas que, de manera más o menos continua, culminó al año siguiente. Aunque no se trató de la primera huelga del mundo del fútbol argentino (la primera fue en 1931 y llevó el deporte al profesionalismo y en 1944 los jueces pararon contra la decisión de la AFA la contratación de jueces ingleses) las consecuencias de la huelga fueron fundamentales para la historia del fútbol en los años sucesivos. El gremio, creado en 1944 gracias al trabajo de algunos jugadores como el portero peruano de Banfield y River Plate, José Soriano, formuló las siguientes propuestas: rechazar de plano cerrar el libro de pase por tres años (que de hecho impedía a los jugadores cambiar equipos hasta el 1951); la eliminación del techo máximo de 1500 dólares de salario y la introducción de un techo mínimo; libertad de acción al término del contrato para los jugadores profesionales (antes existía un pacto entre dirigentes para impedir a los futbolistas sin contracto elegir el equipo con el cual jugar en función de la mejor oferta salarial sin la aprobación del viejo club); la institución de un Tribunal Arbitral al cual se apelase en caso de problemas entre jugadores y clubes; el reconocimiento jurídico del gremio y de la dignidad de trabajadores para los jugadores profesionales (que significaba conseguir todos los derechos que la clase trabajadora argentina ganó en aquellos años). No fue la primera vez que los jugadores, en particular los cracks (así se llamaban los mejores jugadores de la división), querían una mejora contractual. Ya en marzo de 1948 Alfredo Di Stéfano, delantero de River Plate, se enfrentó al club en el momento de renovar el contrato; el jugador pedía un salario de 3000 dólares más otros 150 por cada punto. Al final, Di Stéfano y River llegaron a un compromiso dentro del techo máximo establecido por

\footnotetext{
${ }^{8}$ Cagigal, José María, El deporte en la sociedad actual, Madrid, Editorial Prensa Española, 1975, p. 35.

${ }^{9}$ Reunión presidida por Oscar A. Basso y, en rol se secretarios, Rodolfo Danza y Eduardo Crespi.
} 
la $\mathrm{AFA}^{10}$. Aun así, la "Saeta Rubia" y muchos otros cracks entraron en huelga al siguiente mes contra sus propios clubes.

La petición más importante hecha por la FAA en este momento fue la libre contratación de los jugadores. Desde el comienzo del profesionalismo en 1931, los jugadores no estaban libres de buscar un nuevo equipo al final de sus contratos y el pase solía quedarse en manos de los clubes. Esto significaba que, para cambiar de equipo, los futbolistas tenían que pedir a sus viejos clubes el permiso y, si este no llegaba, no podían cambiar de club. Además, aquel año se decidió cerrar el libro de pases hasta el 1951 y para los jugadores significaba que no podían cambiar de equipo en tres años. El diario Democracia es muy claro sobre las consecuencias del cierre del libro de pase: "El libro de pase abierto significa, sobre todo, libertad de trabajo y el fútbol profesional es una forma de trabajo que la necesita como todas las demás formas de producción" "11.

En cuanto a la cuestión salarial, el gremio quería eliminar el techo máximo salarial y sustituirlo con un salario mínimo y el pleno reconocimiento de beneficios propios del trabajo: aguinaldo, vacaciones de 45 días por años e indemnización por despido. Oscar Basso, presidente de la FAA, en una entrevista a Democracia fue muy claro en sus intenciones:

\footnotetext{
"No tenemos otros caminos a seguir. Puede ser que esta posición de fuerza por nuestra parte resulte para algunos de carácter arbitrario, como si actuásemos aferrados a un capricho, pero es que todo ha llegado como la extemporánea actitud y falta de tacto que no es precisamente nuestra sino de la A. de Fútbol Argentino" $"$.
}

La situación se puede resumir en las palabras de Rodolfo Danza en Democracia: "Reconocimiento por parte de la AFA, o huelga hasta lograrlo" ". Por su parte, los representantes de los clubes se sintieron atacados por los futbolistas a los cuales consideraban equivocados. El presidente de Racing Avellaneda, Carlos Alberto Paillot, aunque comprendía los motivos que llevaron a los futbolistas a la huelga, sostenía que los contratos recién estipulados con el techo máximo salarial constituían la prueba de que la mayoría de los jugadores estaban de acuerdo con los clubes. Para Rodrigo Roselli, secretario de Newell's Old Boys, la huelga era una forma de desconsideración hacia la AFA y los equivocados eran los jugadores al considerarse menospreciados por la federación. José Azurmendi, delegado de Vélez Sarsfield, tenía la misma opinión que Paillot: los jugadores ya habían renovado los contratos y muchos de ellos con un salario mayor que antes. Los tres dirigentes estaban dispuestos a olvidarse de los hechos si los jugadores levantaban el estado de huelga y volvían a jugar, para el placer de los aficionados.

\footnotetext{
${ }^{10}$ Democracia, 6 de marzo de 1948 , p. 16

${ }^{11}$ Democracia, 7 de abril de 1948, p. 15.

${ }^{12}$ Democracia, 10 de abril de 1948, p. 16.

${ }^{13}$ Ibídem.
} 
La AFA se puso rápidamente en una posición de mediación entre las dos partes. El presidente de la federación era Oscar Nicolini, quien fue reelegido en marzo de 1948, siendo descrito por Democracia como "La voz de la razón y la lógica irrefutable de la madurez de nuestro deporte, parte integrante de la madurez nacional" "14. Al mismo tiempo, Democracia consideraba a la AFA como "[...] un organismo que expresa concretamente los resultados de la política recuperadora del general Perón y la consecuente independencia económica"15. Nicolini era un exponente del oficialismo peronista que en esos años controlaba casi directamente la AFA. El 10 de abril decidió intervenir personalmente en el conflicto para encontrar una solución haciéndose cargo del rol de defensor de los aficionados que podían quedarse sin su espectáculo preferido. Nicolini logró la suspensión del estado de huelga; solo la lluvia impidió el comienzo del campeonato de primera división que empezó el domingo después ${ }^{16}$. En los meses sucesivos muchas fueron las reuniones entre FAA y la patronal en el edificio de la calle Viamonte ${ }^{17}$ pero la situación empeoró al final de junio de 1948.

La figura del hincha apareció poco en la discusión entre los jugadores y los clubes pero el interés de los aficionados estuvo más presente en los diarios populares porque, en ese momento, la AFA decidió subir los precios de las entradas en casi un 50\%. El nuevo precio fue fijado a 1,50 dólares la entrada popular y a tres dólares la tribuna oficial. En particular el diario La Época estuvo muy interesado en el tema, poniéndose en una posición muy popular con un artículo titulado "La Época, Intérprete del Clamor Popular, Combate en Forma Enérgica el Aumento de las Entradas. El fútbol debe ser brindado a precios populares". Para el diario "todo le debe el fútbol a ese importantísimo núcleo de hinchas que pertenecen a la auténtica masa de la población laboriosa, pues, merced a la fervorosa adhesión del hincha es que el fútbol en nuestro medio ha alcanzado su extraordinaria difusión y engrandecimiento"18 $\mathrm{y}$, por ello, se pusieron en contra de los dirigentes de los clubes acusados de hacer subir los precios por cubrir el mal estado de las financiaciones de los equipos. En general, solo La Época parece tener interés en los derechos de los hinchas y solo por cuestiones que tenían poco en común con los hechos de la huelga. Los aficionados, al mismo tiempo, fueron utilizados como argumento pacificador por los cuadros de la AFA: Nicolini se propuso como el defensor de los hinchas para proponer su solución a la huelga.

\footnotetext{
${ }^{14}$ Democracia, 2 de marzo de 1948 p. 14.

${ }^{15}$ Ibídem.

${ }^{16}$ El Laborista, 12 de abril de 1948, p. 31.

${ }^{17}$ Sede de la AFA.

${ }^{18}$ La Época, 9 de abril de 1948, p. 32.
} 


\section{El conflicto empeora}

Entre abril y junio de 1948 hubo negociaciones entre la FAA, los clubes y la AFA para resolver el conflicto aunque las partes no pudieron encontrar una solución definitiva. Fue la FAA la que aceleró los eventos. A finales de junio el gremio dio un ultimátum a la AFA y a los clubes: si la situación no se solucionaba por el 28 de aquel mes con la aceptación total de las demandas por parte de los clubes, el gremio y los jugadores entrarían en huelga otra vez ${ }^{19}$. Dos días después, una comisión de la AFA compuesta por los presidentes de varios equipos de primera y segunda división rechazó completamente el pedido de la FAA y, con este acto, empezó un duro conflicto entre jugadores y dirigentes. El uno de julio hubo otra reunión de la comisión en la AFA para decidir cómo afrontar la situación de huelga que amenazaba con dejar el país sin su deporte más popular. Nicolini esta vez decidió no recibir a los representantes de la FAA "por entender que su actitud constituía una falta al compromiso contraído con él”; aun así el gremio logró conseguir un encuentro con el presidente de la AFA el mismo día en los edificios del Ministerio de Hacienda. En la reunión, Nicolini pidió una tregua de una semana para interceder con los dirigentes y el gremio decidió posponer la asamblea de esa noche al día siguiente para discutir la situación ${ }^{20}$ a la luz de las declaraciones del presidente. La reunión gremial no fue exitosa y la comisión de la AFA acusó a los jugadores de falsear los hechos, en particular en lo que concierne al rol de Nicolini:

\footnotetext{
"Es falso que el señor Don Óscar L. M. Nicolini haya solicitado a los jugadores la suspensión de siete días perentorios del estado de huelga. Es falso que el señor Nicolini haya recibido a la entidad gremial que agrupa a los jugadores, por el contrario, mantuvo su decisión de no recibirlos y así se lo hizo saber su secretario privado a la comisión directiva de la misma. Es falso que el señor Basso fue recibido, fuera del despacho del señor Nicolini, por consideración personal y con el objeto de hacerle saber que, si los jugadores no deponían la actitud de violencia, no se podía entrar a considerar alguna forma de arreglo"21.
}

Las resoluciones adoptadas fueron muchas pero las más importantes fueron el rechazo de las supuestas falsedades del gremio, la suspensión de la práctica del fútbol profesional, amistosos incluidos, y constituir al Consejo de la AFA en comisión permanente.

Por su parte, los futbolistas publicaron un comunicado muy extenso para responder a las acusaciones de la comisión. La FAA abrió un expediente en la Secretaría del Trabajo (Expediente n.3874-f-48) para responder al hecho de que, desde la creación del gremio, la

${ }^{19}$ El Laborista, 19 de junio de 1948, p. 23. Para ver las propuestas completas del gremio, Democracia, 29 de junio de 1948, p. 16.

${ }^{20}$ El Laborista, 6 de abril de 1948, p. 32

${ }^{21}$ El Laborista, 7 de abril de 1948, p. 32 
AFA reconoció la organización solo en 1948 después de tres años y la secretaría encontró, según la FAA, irregularidades en el modo de operar de la AFA. También expresaron que el largo tiempo trascurrido sin poder llegar a una discusión del problema motivó la decisión de declarar la huelga a finales de junio. Las resoluciones del gremio rechazaron completamente las acusaciones de la AFA y expresaron el deseo de los jugadores, ajenos a fines publicitarios, de poder jugar los partidos en el interior programados entre el 9 y el 11 de julio ${ }^{22}$. La pelea en los días fue muy dura y ninguna de las dos partes quería cambiar de posición. Vicente de la Matta, jugador de Independiente, expresó la unidad de intentos de los jugadores pero a la vez mucha confianza en el trabajo de los dirigentes de su club tanto que:

"ni he retirado la copia de contrato que me corresponde. Independiente es un banco y sus dirigentes gozan de mi absoluta confianza. [...] Pero la situación es otra y naturalmente yo en todo estoy con mis compañeros. [...] Nosotros no hicimos este movimiento para beneficiarnos sino para los profesionales del futuro actúen en un medio más digno del que deben actuar muchos de los actuales jugadores" ${ }^{23}$.

El 6 de julio se reunieron los jugadores y el presidente de la AFA para lograr un acuerdo y la discusión se desarrolló en los cuatros días siguientes en las oficinas de la Telefónica Argentina. El acuerdo llegó el sábado 10 de julio con los futbolistas que decidieron levantar la huelga y reunirse el lunes 12 para estudiar las peticiones. El acta firmada señalaba que:

“1) Simultáneamente, los Futbolistas Argentinos Agremiados y laAFA, levantan la huelga declarada en la fecha 28 de junio próximo pasado, y la suspensión provisoria del campeonato profesional dispuesta el 3 de julio próximo pasado. 2) A partir de la fecha de este acuerdo, la Comisión Especial de la AFA y la comisión paritaria de la Futbolistas Agremiados se constituyen en sesión permanente diaria al efecto de proceder al estudio del petitorio presentado por estos últimos dejándose expresa la constancia de que ambas comisiones cuentan en plenos poderes para resolver todas la cuestiones del litigio, con excepción de la contratación libre, decisión que deberá ser sometida a la consideración de las asamblea de la AFA y de los Futbolistas Agremiados respectivamente. 3) Se dará precedencia al conflicto de los jugadores individualmente considerados, los que revolverán en la primera semana, a partir de la fecha de este convenio y en lo que se refiere el estudio del petitorio, 15 días, sin perjuicio de que, si al vencimiento de este plazo no hubiera podido resolver razonablemente la cuestión en discusión, el mismo se prorrogará"24.

En los días y meses siguientes, hubo muchas reuniones en el edificio de la AFA y, en un principio, parecía prevaler un criterio de conciliación. Ya al final del mes de julio fue aprobada

\footnotetext{
$\overline{{ }^{22} \text { El Laborista, } 9}$ de abril de 1948, p. 32.

${ }^{23 E l}$ Laborista, 6 de julio de 1948 , p. 32.

${ }^{24}$ Democracia, 11 de julio de 1948, p. 16.
} 
la instauración de un sueldo mínimo de 300 dólares para los jugadores de segunda división, aunque se especificaba que el futbolista podía aceptar un sueldo menor y que, en caso de contrato inferior al mínimo establecido, el jugador estaba libre de fichar por otros clubes. La votación, en la cual participaron todos los clubes de segunda división y el presidente de categoría Raúl H. Colombo, fue aprobada con trece votos a favor y cuatro en contra ${ }^{25}$. Al mismo tiempo, también la discusión por la contratación libre de los clubes de primera división estaba en marcha aunque la mayoría de las reuniones se realizaban de manera secreta.

Julio fue un mes muy convulso ya que, por primera vez desde la llegada del profesionalismo, el país se quedó sin fútbol dos semanas. Estos "Domingos sin fútbol” fueron muy importantes en el imaginario colectivo de la gente y en particular de los hinchas y la atención de los diarios al problema de la afición fue constante. Empezando con Democracia, es muy interesante la rúbrica de Víctor Díez, que publicaba versos y poesías en las páginas deportivas del diario. El uno de julio publicó una poesía intitulada “¡No Muchachos!” en la cual pide a los jugadores que "no nos dejen sin fútbol el domingo, pues él es el nuestro mate y pan con grasa. [...] El que niega los pies a la pelota, le quita la quebrada a nuestro tango" 26 . Para el autor, el fútbol es parte integrante de la sociedad y del vivir del hincha, tan importante como la yerba mate, el pan y el tango. En otra poesía del 4 julio, titulada “¡Sin Fútbol!”, Díez dice que: “Las canchas no tendrán fuego ni brillo, hoy sin fútbol nos falta cigarrillo, ¡Hoy quedamos con ganas de fumar!”. Para finalizar, una vez que los jugadores levantaron la huelga, Díez expuso toda su felicidad en la poesía “¡Fútbol!”: “Muchachos ¡hoy de nuevo habrá emoción! [...] ¡Sí muchachos!, ¡el fútbol otra vez! ¡perdimos la cabeza por los pies, y hoy los pies nos devuelve la cabeza!" ${ }^{27}$. Al mismo tiempo publicaron artículos sobre las maneras en la cual algunos hinchas pasaron el domingo sin fútbol, pero el tono melodramático parece más propio de un cuento que de un artículo de diario:

\footnotetext{
“Dónde va? ¡Al cine! Sonríe. Pero ese «esta tarde voy al cine», suena con la misma tristeza del tango que gritaba: «esta noche me emborracho bien». [...] En las colas de los cines que comienzan a las once, en los cafés emborrachándose de humo, ya que no puede hacerlo de emociones, en el hipódromo jugando «tres y dos» sin ganas de ganar. En las calles, en las canchas donde juegan las cuartas y quintas. $\mathrm{Y}$ especialmente, en la melancolía que vive la tarde porteña sin su «espectáculo». ¡Sin fútbol!”’28.
}

Cuando el campeonato volvió después de dos semanas de paro, el diario publicó dos artículos de júbilo por el hincha. Democracia no dedicó a los aficionados mucho espacio en sus páginas ya que era la hípica y no el fútbol el deporte más importante para el diario. Las

\footnotetext{
$\overline{{ }^{25} \text { Democracia, } 27}$ de julio de 1948 , p. 15.

${ }^{26}$ Democracia, 1 de julio de 1948 , p. 16.

${ }^{27}$ Las tres poesías se pueden encontrar respectivamente en Democracia: la primera, el 1 de julio de 1948, p. 16; la segunda, el 4 de julio de 1948, p. 16; la tercera, el 18 de julio de 1948, p. 16;

${ }^{28}$ Democracia, 4 de julio de 1948 , p. 16.
} 
historietas del tema deportivo de El Laborista durante el mes de julio dibujaban al hincha siempre preocupado, pensando en fútbol en cada momento de su vida cotidiana, casi obsesionado, y que intentaba sustituir su deporte preferido con otros o con los partidos del campeonato juvenil. El 5 de julio escribía el diario: "Nadie tendrá la culpa, pero al hincha le robaron su espectáculo preferido" expresando su preocupación por el hincha. A diferencia de Democracia, el hincha de El Laborista estaba descrito como irascible y molesto ${ }^{29}$. El fútbol en este caso está entendido como un medio de control de la población y de "válvula de escape" social donde la parte más violenta de la población puede expresarse en un contexto controlado. Sin el futbol, los violentos no tienen lugares donde ir o peor, se iban a lugares con menor control.

La Época, como pasó en abril, fue el diario más interesado en la suerte de los hinchas que en los hechos de la huelga. El diario se hizo portador de los derechos de los hinchas, los cuales tenían un "derecho al pataleo", y pedía a los hinchas escribir sus opiniones sobre la huelga. En general, las mismas posiciones que se pueden encontrar en los otros diarios, se encontraban en La Época con la excepción de la preocupación de que el deporte más popular del país no vuelva a ser una empresa comercial ${ }^{30}$.

Las cosas parecieron volver a la normalidad para finales de julio, pero el problema apareció otra vez en noviembre, cuando los jugadores declararon la huelga por última vez.

\section{Ruptura completa}

Durante algunos meses las relaciones entre AFA y FAA siguieron tensas. En particular, fue la libre contratación de los jugadores el punto más complicado para ambas partes y el gremio comenzó a perder la paciencia esperando una solución. A comienzos de octubre la FAA llamó a una asamblea para el 20 de ese mes para decidir la estrategia a seguir. El día después, el consejo de la AFA dio a conocer la elaboración de un plan denominado "Anteproyecto de Régimen de Contratación de Jugadores" y empezaron a discutir ese plan a partir del 27 de octubre. Aunque las asociaciones se cuidaron de comunicar que no estaban en conflicto, la situación era muy problemática por casos como lo ocurrido con algunos jugadores de Huracán que fueron declarados libres por su club pero no podían ser contratados ni por sus viejos clubes ni por otros clubes de las ligas afiliadas a la $\mathrm{AFA}^{31}$. La situación empeoró rápidamente; el domingo 31 de octubre los jugadores hicieron un paro de un minuto durante los partidos del campeonato y el jueves siguiente los presidentes se reunieron en los edificios de Correos y Telecomunicaciones

\footnotetext{
$\overline{{ }^{29} \text { El Laborista, } 5}$ de julio de 1948, p. 12.

${ }^{30}$ La Época, 5 de julio de 1948, p. 14.

${ }^{31}$ Democracia, 27 de octubre de 1948, p. 16.
} 
para discutir los hechos recientes. La resolución final de esa reunión decretaba los siguientes términos: convocar una reunión con la finalidad de suspender el fútbol profesional y volver al amateurismo; aceptar la renuncia de José M. Covatto y de Raúl Colombo, ambos miembros del Tribunado Arbitral; hacerse cargo del pago de 11000 dólares a jugadores en vías de cobro; encargar a la Comisión de Concurso presentar un programa de partidos por un campeonato amateur realizable inmediatamente; un voto de confianza a Nicolini por su actitud favorable al amateurismo $0^{32}$.

Durante los días siguientes hubo muchas reuniones en los oficios del Ministerio de Hacienda bajo la supervisión de Raúl A. Cereijo, titular del ministerio desde 1946. El 8 de noviembre la AFA dio a conocer los éxitos de una larga reunión en la cual se resolvió que: los torneos profesionales serían reanudados a partir del fin de semana sucesivo (como homenaje a la afición); se declararon terminadas todas las tramitaciones existentes y todo lo negociado con la FAA y la temática de los derechos de los jugadores pasaba a competencia exclusiva de la Secretaria de Trabajo y Previsión ${ }^{33}$. Los jugadores, de hecho, vieron cómo se perdía cualquier posibilidad de contratación y toda la legitimidad que ganó el gremio después este golpe de mano y la AFA amenazó con suspender por dos años a todos los profesionales que decidieran terminar sus contratos (aplicación del artículo 25 del reglamento de la AFA) ${ }^{34}$. Nicolini explicó la situación diciendo que la asociación no desconocía los derechos de los jugadores pero que la AFA estaba dispuesta a aceptar solo las disposiciones elaboradas por la Secretaría de Trabajo y Previsión.

La secretaría, como primera medida, puso como condición para empezar la contratación el fin de la huelga, aunque los delegados sindicales no respondieron a la petición y no tomaron decisiones en ese momento. Solo los clubes de Rosario y sus jugadores anunciaron que el domingo jugarían regularmente sus partidos ${ }^{35}$. Durante el fin de semana, la huelga no se terminó y los equipos salieron a las canchas con los equipos juveniles y los clubes mantuvieron su promesa de sancionar por dos años a los jugadores que no se presentaron en las canchas poniendo fin a sus contratos (en total, fueron 539 los contratos resueltos entre clubes de primera y segunda división $\left.{ }^{36}\right)$. En un comunicado a los hinchas, la FAA explicó su posición aclarando que en ningún momento la secretaría llamó al gremio para conocer los hechos del conflicto contra la AFA y que, en ningún caso, los jugadores hacían eso por lucro sino por dignidad, por volver más decente el régimen de contratos y por el fiel acatamiento a lo pactado. Esta vez no hubo en el gremio gran cooperación entre jugadores y empezaron las primeras deserciones. José Ramos, delantero de River Plate, fue el primer crack en renunciar a la afiliación gremial y volver a su club, ya a mediados del mes de noviembre. Ramos apoyó su decisión acusando al

\footnotetext{
$\overline{{ }^{32} \text { Democracia, } 4}$ de noviembre de 1948, p. 15.

${ }^{33}$ El Laborista, 9 de noviembre de 1948, p. 15.

${ }^{34}$ El Laborista, 11 de noviembre de 1948, p. 18.

${ }^{35}$ Ibidem.

${ }^{36}$ Democracia, 19 de noviembre de 1948. P. 16.
} 
gremio de no haber escuchado el consejo de la Secretaría de Trabajo y Previsión de terminar la huelga y que la intransigencia de la agrupación estaba injustificada. Ramos también manifestó mucha gratitud por su club en el cual pasó los últimos quince años y al cual debía su bienestar y su renombre ${ }^{37}$. Después de Ramos, fueron los jugadores de Colón de Santa Fe los que, en una carta a Nicolini, comunicaron que deponían el estado de solidaridad con la agrupación gremial y, al mismo tiempo, también el portero de River Amadeo Carrizo dejó el gremio ${ }^{38}$. La huelga fue levantada solo a fines de noviembre, cuando la FAA aceptó la intervención de la secretaría en el conflicto ${ }^{39}$.

A comienzos de enero de 1949, fue aprobado el nuevo régimen contractual del fútbol por la AFA. Entre las novedades, las más importantes eran el sueldo mínimo y la contratación de los jugadores. El salario de los jugadores profesionales fue del $30 \%$ de las recaudaciones líquidas (venta de boletos de entrada y platea) que correspondían a cada club y que, de esta suma, el $30 \%$ eran para los jugadores que actuaron en el partido, el $20 \%$ para los jugadores integrados (que no jugaron el partido o del equipo de reserva) y el otro $30 \%$ estaba disponible como premio personal a discreción de los clubes. Además, fue introducida una cláusula que impedía a los clubes invertir en adquisición por una suma superior al 20\% de la suma correspondiente al año anterior a sus integrantes. Sustancialmente se quedó el tope salarial sin introducir el salario mínimo. Respecto a la libre contratación de los jugadores, fue establecido que los contratos no podían tener duración superior a tres años y al final del contrato estaban libres de contraer acuerdos con cualquier equipo. En el nuevo reglamento no figura la FAA como responsable del control sobre los contratos de los jugadores (que era competencia del Consejo Directivo de la AFA), pero se reconoce la existencia y la importancia de la asociación en su rol de intermediario entre jugadores y clubes ${ }^{40}$. Solo en mayo de 1949 el gremio fue reconocido con personalidad jurídica y en junio la FAA firmó la Convención Colectiva de Trabajo número 6/49 donde fue introducido el techo mínimo salarial, dejando igual el techo máximo de 1500 dólares.

Los efectos de la huelga no terminaron en junio del 1949. Aunque muchos jugadores se quedaron bajo el nuevo régimen futbolístico de la AFA, muchos más fueron los jugadores que decidieron dejar el país e ir a jugar al extranjero. Fue calculado que más de cien atletas se fueron al extranjero, en particular a Italia, Uruguay, Colombia y Perú. En Colombia los cracks fundaron una nueva liga profesional (Dimayor, a la cual pertenecían también algunos equipos peruanos) y algunos equipos como Millonarios, donde la mayoría de los jugadores venían de River Plate y eran titulares en la selección. Esta liga no tuvo reconocimiento legal por la Fifa hasta el 1951 cuando se firmó el Pacto de Lima entre las federaciones de Argentina, Colombia y Perú, que la cerró ${ }^{41}$. A nivel deportivo, el éxodo en masa de los cracks es la base de la crisis del fútbol argentino en las competiciones internacionales de los años sucesivos, porque solo quien jugaba en equipos nacionales podía ser elegido para la selección. Argentina

\footnotetext{
$\overline{{ }^{37} \text { Democracia, } 17}$ de noviembre de 1948 , p. 16.

${ }^{38}$ El Laborista, 20 de noviembre de 1948, p. 16.

${ }^{39}$ El Laborista, 25 de noviembre de 1948, p. 15.

${ }^{40}$ Democracia, 14 de enero de 1949 , p. 15.

${ }^{41}$ Molinari Alejandro, y Roberto Martínez, El Fútbol. La conquista ... op. cit., pp. 184 y 185.
} 
no pudo participar en competiciones internacionales hasta 1954 (y ese año no participó en la copa Rimet por voluntad de Perón) y la crisis encontró su zenit en el partido perdido por 6-1 contra Checoslovaquia durante las fases finales de la Copa Rimet 1958 en Suecia. Bajo el nivel sindical, tampoco el conflicto estaba terminado. Solo en 1971, después una larga huelga, fue aprobado el estatuto del fútbol profesional y se cerraron también por parte del gremio todas las cuestiones nacidas al final de los años cuarenta.

A diferencia de lo que pasó en abril y en julio, en noviembre el espectro de los domingos sin fútbol fue evitado. A partir del comienzo del conflicto, fue aprobado un plan para no dejar a los aficionados sin fútbol, haciendo jugar a los equipos juveniles y elevando los partidos del torneo de fútbol infantil Evita Perón (que hace años jugaban las fases finales en Nuñez, en la cancha de River Plate) a la misma importancia de los partidos de Primera División. Al mismo tiempo, el costo de las entradas a las canchas fue bajado a un peso para ver los partidos de campeonato con los equipos juveniles ${ }^{42}$. Los diarios parecían apreciar esta solución y se pudo ver un cambio sustancial en su trabajo; si antes estaban con los jugadores (y se quedaron en esta posición hasta la mitad de noviembre) después empezaron a atacar a los futbolistas, culpables de no aceptar la intervención de la Secretaría de Trabajo y Previsión. Democracia publicó un artículo titulado "Podrá Faltar la Calidad de los Cracks, pero Sobrará Fervor y Entusiasmo de Juventud" en el cual toma este hecho como el punto de comienzo de un nuevo fútbol argentino y la creación de nuevos héroes populares que vayan a remplazar a los viejos que disfrutaron del privilegio de jugar en primera división ${ }^{43}$. El más visible cambio de posición fue de $L a$ Época que empezó a atacar el gremio en sus artículos. Artículos como "Deben Renunciar los Dirigentes Gremiales de los Futbolistas"44 y "Quiénes Han Mantenido la Huelga, Contra el Criterio más Elemental, Solo Perjudican con Ello, los intereses que Pretenden Defender”45, son un verdadero ataque al gremio y a los futbolistas. La Época levantó también una controversia sobre el pago de los jugadores considerados "principescos", pero siempre quedándose en una posición de defensa del hincha: "El aficionado y, para ser más sinceros, el hincha que con su apasionamiento característico ha empujado su bandera para defender sus puntos de vista, debe ante todo saber un poco de política administrativa antes de discernir y emitir su opinión tan verdadera como las otras"46. En pocas palabras, el hincha tenía todo el derecho de expresar su opinión por un futbol con muchos cracks, pero este tipo de futbol tenía un precio y estaba bien que el aficionado conociera también la situación. La Época hizo un trabajo muy detallado sobre el pago de los atletas, algo que no aparecía en los otros diarios peronistas. La razón de este interés respecto al aspecto más económico de la huelga tiene sus raíces en el debate entre amateurismo y profesionalismo. Una de las estrategias del oficialismo peronista fue la amenaza de desconocer completamente el profesionalismo en el fútbol pidiendo varias veces el regreso al auateurismo (la exaltación de los torneos juveniles también puede ser leída bajo este marco,

\footnotetext{
$\overline{{ }^{42} \text { El Laborista, } 16}$ de noviembre de 1948, p. 16.

${ }^{43}$ Democracia, 14 de noviembre de 1948, p. 14.

${ }^{44}$ La Época, 17 de noviembre de 1948, p. 11.

${ }^{45}$ La Epoca, 15 de noviembre de 1948, p. 11.

${ }^{46}$ La Epoca, 29 de noviembre de 1948, p. 11.
} 
con jóvenes jugadores que representaban la parte buena del deporte frente a los profesionales, que solamente querían ganar dinero con el fútbol). El diario siempre pareció quedarse cerca del oficialismo y no parece raro que en esta fase final de la huelga La Época decidiera exponer el enorme gasto de dinero en que se había convertido el futbol nacional, contradiciendo la posición inicial que era de un respaldo general a las demandas de los jugadores.

\section{Conclusiones}

Al comienzo de este trabajo planteé la siguiente pregunta: ¿cómo la prensa peronista se posicionó en la pelea entre jugadores y clubes? A la luz de lo explicado en las últimas páginas, podemos decir que la prensa peronista en examen (Democracia, El Laborista y La Época) tuvo una posición favorable a la huelga y las demandas de los jugadores la mayoría del tiempo. Solo después de la mitad de noviembre de 1948, cuando en la disputa entró la Secretaría de Trabajo y Previsión, cambiaron su posición pidiendo a los jugadores que levantaran la huelga y negociaran con la AFA bajo la supervisión de la secretaría. En todo este proceso, nunca se olvidó, por parte de la prensa, el rol del hincha que era no solo el consumidor final del espectáculo sino el verdadero objeto de interés de los diarios, especialmente a partir de julio de 1948.

Los resultados de esta huelga fueron muy importantes para el fútbol argentino. En 1949 muchos cracks se fueron a Colombia después de la decisión de seguir con el techo máximo de mil quinientos pesos, donde fundaron la primera liga de fútbol profesional y algunos equipos como los Millonarios de Bogotá (aunque ya existía una liga profesional reconocida por la FIFA). Este éxodo llevó a un empobrecimiento del deporte nacional. Argentina no participó en la Copa Rimet hasta 1958 (en 1950 no se clasificó y en 1954 no participó por orden de Perón, que no estaba seguro de poder ganar la competición) y en ese campeonato sucedió la debacle de 6-1 contra Checoslovaquia que marcó el momento más bajo del deporte argentino. Solo con una segunda huelga en 1971-72 los futbolistas consiguieron un estatuto que regulaba el contrato entre jugadores y clubes y una carta de derechos comparable con la de los otros trabajadores, finalizando así la discusión que empezó con la huelga de 1948. El otro gran perdedor de la huelga fue el Racing que perdió el campeonato de Primera División contra a los odiados rivales del Independiente gracias a la suspensión anticipada de los partidos.

No se concretó el retorno al amateurismo, tan auspiciado por los dirigentes y los cuadros del partido peronista; el conjunto de intereses que se formaron en casi veinte años de profesionalismo fueron demasiado importantes para decidir cancelar todo. Aun así, en los años del primer peronismo, hubo muchas inversiones en la promoción del deporte juvenil y amateur, en particular con la organización de los Torneos Evita Perón y con los Campeonatos Universitarios. 